\title{
Charity Pharmaceutical Care Services: a New Initiative Project in Saudi Arabia
}

\author{
Yousef Ahmed Alomi*, (D) BSC. \\ Pharm, MSc. Clin Pharm, BCPS, \\ BCNSP, DiBA, CDE Critical Care Clinical \\ Pharmacists TPN Clinical Pharmacist, \\ Freelancer Business Planner, Content \\ Editor, and Data Analyst, Riyadh, \\ Saudi Arabia. \\ Abeer Hussin Almasoudi, BSc. \\ Pharm, Director, Administration of \\ Research and Studies, Ministry of \\ Health, Tabuk, Saudi Arabia.
}

\section{Correspondence:}

Dr. Yousef Ahmed Alomi, BSc. Pharm, MSc. Clin Pharm, BCPS, BCNSP, DiBA, CDE

Critical Care Clinical Pharmacists

TPN Clinical Pharmacist, Freelancer Business Planner, Content Editor, and

Data Analyst, P.O.BOX 100, Riyadh

11392, Riyadh, SAUDI ARABIA.

Phone no: +966504417712

E-mail:yalomi@gmail.com

Received: 23-12-2020

Approved: 17-02-2021

Copyright: ๑ the author(s),publisher and licensee Pharmacology, Toxicology and Biomedical Reports. This is an open-access article distributed under the terms of the Creative Commons Attribution NonCommercial License, which permits unrestricted non-commercial use, distribution, and reproduction in any medium, provided the original work is properly cited.

This is an open access article distributed under the terms of the Creative Commons Attribution-NonCommercial-ShareAlike 4.0 License

Access this article online

\begin{tabular}{|c|c|}
\hline & www.ptbreports.org \\
& DOI: \\
&
\end{tabular}

\begin{abstract}
Objectives: To affirm the Charity pharmaceutical care services as new initiatives in the Kingdom of Saudi Arabia. Methods: It is a new initiative project drove by national Charity heath care services societies and regulations. The projects expressed from the international business model, pharmacy project guidelines project management institution guidelines of a new project. The initiative project is written through project management professionals and entails of several parts, including the initial and planning phases, the execution phase, and the monitoring and controlling phase. Results: The Charity pharmaceutical care services with a defined vision, mission, and goals. The services had numerous benefits, counting clinical and economical on patients, as illustrated in the review. The continuation of the project is guaranteed by the risk management model description. In addition, the monitoring and controlling of the services as declared. Finally, the transition to operation project through closing project stage is discovered in the analysis. Conclusion: The Charity pharmaceutical care services are a new initiative part of the charity medical and healthcare services. The Charity pharmaceutical care services were part of pharmacy strategic plan with Saudi vision 2030, meet the demand of healthcare services, and diminish the economic burden on the healthcare system; it is highly proposed to implement in Saudi Arabia.

Key words: Charity, Pharmaceutical care, Pharmacy, Services, Initiative, Saudi Arabia.
\end{abstract}

\section{INTRODUCTION}

The healthcare services are delivered through three sectors. The Ministry of Health covered almost $60 \%$ of Saudi populations, while non- $\mathrm{MOH}$ governmental sectors covered $20 \%$, and private sectors covered another $20 \% .^{1,2}$ The majority of three sectors aided their patients of the healthcare services through health insurance according to the new Saudi strategic plan 2030..$^{3-5}$ The charitable performances and works are mammoth in the Kingdom of Saudi Arabia. They deliver all charitable activities through charity non-medical organizations. However, in the past 5-10 years, various charity institutions or non-profit scientific organizations had been established as declared in Table $1{ }^{6,7}$ The institutions cover different healthcare specialties, counting oncology, smoking cessation, paediatric oncology, renal failure, genetic diseases, AIDS, Diabetes Mellitus, and Alzheimer's disease. ${ }^{8}$ However, few or organizations take care of pharmacy or pharmaceutical care except the non-profit scientific societies. Besides, the most momentous organizations for charitable healthcare performance was recognized before several years by name King Salman Humanitarian Aid and Relief Center (KS relief) for to cover all regions in Saudi and all developing countries around the world. ${ }^{9}$ The center had a part of charitable pharmaceutical care performance through medications procurement, and distribution to the developing countries or any country had disaster problems. Moreover, recently the Ministry of open health administration to take care of volunteer healthcare providers, counting the pharmacy staff. Numerous studies deliberated the charity healthcare providers through different specialties and performances. ${ }^{10-15}$ Besides, the pharmacist contributed to charity pharmaceutical services with various types of performances, counting clinical pharmacy activities. ${ }^{16-20}$ The local study showed that healthcare providers participate as volunteer jobs through the mass gathering medicine Hajj period. ${ }^{21}$ However, the author is not acquainted with any scientific research about charity pharmaceutical care in Saudi Arabia or the Gulf and Middle East countries. This review project goals to declare charity pharmaceutical care as a new initiatives project in Saudi Arabia.

\section{Method of the Project}

It is a new initiative project drove by the international charity healthcare organizations programs. The task force team of charity pharmacy from the author's expertise in charity healthcare professionals. The committee focussed and drove the charity pharmacy and medical guidelines from the textbook and international literature of charity pharmacies. It was written by exploiting the international business model, pharmacy project guidelines, and project management institution guidelines. ${ }^{22-25}$ The charity pharmacy contained of type charity pharmacy, charity pharmacy benefits, how to implement charity pharmacy, the role of the pharmacist in charity healthcare services. The project is written through project management professionals and entails of several parts, counting the initial and planning phases, the execution phase, and the monitoring and controlling phase. 
Table 1: The Charity Medical Societies. ${ }^{[6-8]}$

\begin{tabular}{|c|c|c|c|c|}
\hline No & Name of society & $\begin{array}{c}\text { Year of } \\
\text { establishment }\end{array}$ & Website & Twitter \\
\hline 1 & The Saudi pharmaceutical society & 1408 & https://www.saudipharmsociety.com/ & @SaudiPhSociety \\
\hline 2 & Saudi Society of Clinical Pharmacy & 2018 & https://sscp.org.sa/ar/home/ & @SSCP_KSA \\
\hline 3 & Saudi Society of Family and Community Medicine & 1411 & http://www.ssfcm.org/public/arabic/index/ & @SSFCM_org \\
\hline 4 & The Saudi Society For Evidence-Based Health Care & $27-2-1425$ & http://www.borhan.org.sa/ & ------ \\
\hline 5 & Saudi Allergy, Asthma and Immunology Society & ------ & https://saais.org.sa/ar & @SaudiAAIS \\
\hline 6 & Saudi Epilepsy Society & $8-9-1430$ & ------- & @Saudi_ES \\
\hline 7 & Saudi Society of Emergency Medicine & $12-1-1427$ & http://sasem.org.sa/ & @SaudiEmergency \\
\hline 8 & Saudi Oncology Society & $12-2-1427$ & http://saudioncology.org/main/ & \\
\hline 9 & Saudi Society of Forensic Medicine & 2008 & http://www.ssfm.org.sa/ & @SaudiForensic \\
\hline 10 & Saudi Society of Medical Genetics & 2009 & http://www.ssmg.org.sa/en/ & @SSMG_genetic \\
\hline 11 & Saudi Society For Health Administration & ------- & http://ssha.org.sa/ & @Saudi_SHA \\
\hline 12 & Saudi Society Of Endocrinology and Metabolism & ------ & https://sdea.org.sa/en/ & @SDEASAUDI1 \\
\hline 13 & Saudi Heart Association & ------ & https://saudi-heart.com/ & @SHA_media \\
\hline 14 & Saudi Society of Dermatology and Dermatologic Surgery & 1989 & https://ssdds.org/ & @ssdds_org \\
\hline 15 & Saudi Anesthetic Society & 13-9-1998 & http://www.saudianas.com/ & \\
\hline 16 & Saudi Neonatology Society & 21-11-2006 & http://www.sns.med.sa/ & @SaudiSns \\
\hline 17 & Saudi Gastrointestinal Association & ------ & https://www.saudigastro.com/ & @SGA_KSA \\
\hline 18 & Society of Nephrology and Transplantation & ------ & http://ssn-sa.com/language/ar/home-arabic/ & @saudi_SSN \\
\hline 19 & $\begin{array}{l}\text { The Saudi Society of Pediatric Gastroenterology, } \\
\text { Hepatology and Nutrition }\end{array}$ & 2008 & http://www.saspghan.org/public/arabic & ------ \\
\hline 20 & Saudi Critical Care Society & ------- & http://sccs-sa.org/ & ------- \\
\hline 21 & Saudi Stroke Society & $1-6-2006$ & https://stroke.org.sa/ar/ & ------- \\
\hline 22 & Hypertension Management Society & & https://saudihtn.org/ & ------- \\
\hline 23 & Saudi Pediatric Neurology Society & 26-6-1432 & ------- & @SpnsSa \\
\hline 24 & Saudi Neurology Society & $18-11-1432$ & http://www.saudineurology.org/ & ------- \\
\hline
\end{tabular}

\section{Initiative Phase}

\section{Assessment Needs}

The workload number of clinical pharmacists or distributive and pharmacies are few in the Kingdom of Saudi Arabia. However, the requirements and forecasting of pharmacy staff are very high either during regular days or during mass gatherings pharmaceutical care Hajj or Omera period at all types of healthcare organizations, counting the Ministry of healthcare institutions. Despite high demand, the annually new graduate of pharmacists will not cover the request or the requirements of the workforce of pharmacy staff. Thus, the workforce of pharmacy staff mandatory other resources to cover all pharmacy services need for all patients in Saudi Arabia. One of the solutions is to create non-paid or not-profit or charity healthcare organizations to evaluate the governmental and private healthcare services institutions. Charity pharmaceutical care had been executed through a few pharmaceutical sciences societies and charity pharmacy societies. Besides, the charity of pharmacy performance existed through scientific healthcare societies or charity or not profit healthcare societies. Other charity pharmaceuticals care not lived, for instance, the charity community pharmacies. Besides, in some charitable programs, the pharmacists seldom contribute in it through mass gatherings medicine or healthcare organizations.

Moreover, during the holy month of Ramadan, several queries raise for drug therapy and fasting. Although the pharmacist delivers services during fasting, there is no charity pharmacist to take care of the full-time job of Ramadan pharmaceutical care. In addition, the numerous factors of the workforce may disturb the safety culture and lead to medication errors. In some cases, it might increase questions about medications during the holy month of Ramadan. Therefore, it extremely demands charity pharmaceutical services to solve all earlier issues and situations.

\section{SWOT Analysis}

The SWOT analysis is measured one of the conventional methods for each new project analysis. The SWOT analysis includes strengths, weaknesses, opportunities, and threats. The strengths points of the project are setting up the charity pharmaceutical care services, implementing medication safety to prevent mistakes, dipping pharmacy and healthcare provider workload of other non-charity pharmaceutical care services. In contrast, the weak points are charity pharmacy staff and poor knowledge of charity pharmaceutical care services. The opportunities points are quality happens the strategic plan of Saudi 2030, including initiatives and program implementation. Finally, the threat points are if the charity pharmacy strategic plan does not occur and the administration planner is inaccessible.

\section{Market Analysis}

The majority of the pharmaceutical care services recognised for governmental and private healthcare organizations had precise. The pharmacy 
services entailed of various sections, including inpatient, outpatient services, clinical pharmacy services, multiple pharmacy practices, pharmacy administration programs, and mandatory to implement the Saudi center for healthcare accreditation (CBAHI) and the joint commission of hospital accreditation. The majority of healthcare institutions implemented international pharmaceutical care standards. However, the charity of Pharmaceutical care services was not avowed, and neither existed in Saudi Arabia. Some charity pharmaceutical-related healthcare and pharmacy societies are excited as discovered in Table 1, and the clinical pharmacist or pharmacists and pharmacy technicians can participate in it. Besides, the center of charity healthcare providers lately established at the Ministry of Health guide the people to contribute in charity healthcare services, counting pharmaceutical care services. ${ }^{6,7}$

\section{Planning Phase}

\section{Scope of the Project}

The project covers charity pharmaceutical care services counting the benefit of charity pharmaceutical care, the common types of charity pharmacy practice, the program of charity pharmacy, and the administration of charity pharmaceutical care services.

\section{Vision, Missions, Goals}

The project's vision is to influence the best charity pharmaceutical care, while the message is to deliver the appropriate charity pharmaceutical care performance to the medical organizations and populations. The goals of the project are the following:

- Set-up the strategic objectives of the pharmacist's charitable work and fix the charity pharmaceutical care services.

- $\quad$ Providing the charity pharmaceutical service to the poor people and remote areas Adopting pharmaceutical care and environmental issues for disasters.

- Implement the role of pharmaceutical care in charitable societies.

- Providing pharmaceutical care for pilgrims and contributing to the mass gatherings pharmaceutical care hajj and Omera.

- Contributing to the development of charity pharmaceutical research that serves in the Islamic environment.

- Providing Ramadan Pharmaceutical care during fasting the holy month of Ramadan and contribute the drug therapy during Fasting Ramadan.

- Contribute to disaster medicine and emergency public health services.

- Contribute to formulating a pharmacy experience based on Islamic values.

- Contribute to finding a legal reference for Muslim pharmacists to monitor their proposals and projects and answer their questions and explorations during pharmacy practice.

- $\quad$ Recalling and publishing the history of Islamic charity pharmacy and inspiring the study of prophetic medicine.

- They are promoting from the profession of pharmacy care in advocating Islam and correcting concepts.

\section{Project Description}

The following policies were put in place for every pharmacy staff and other health care individuals:

- The charity pharmaceutical care should be expressed at the pharmacy department of each healthcare institution.

- The charity pharmaceutical care committee should entail of a Charity clinical pharmacist, distributive pharmacist and pharmacy technician, charity physician, and nursing representative.

- The charity pharmaceutical care committee rereads charity pharmaceutical care standards and regulations and updates at least annually.
- The committee should regulate charity pharmaceutical care education and training sessions for all pharmacy staff and healthcare providers.

- The charity pharmaceutical care is dispersed to healthcare sectors at all institutions.

- The pharmacist participate in the pharmacy charity according to the goals and objectives of charity pharmaceutical care

- The pharmacist, the one to two types of charity pharmaceutical work as follows:

- Charity hospital pharmacy

- Charity community pharmacy

- Charity ambulatory care services

- Ramadan Pharmaceutical care

- Mass gatherings Hajj or Omera pharmaceutical care

- Charity pharmaceutical societies

- Charity healthcare societies

- Islamic history of pharmacy

- Prophet medicine

- Islamic value in pharmacy and medicine

- Disaster medicine and emergency public health

- Research in charity pharmaceutical care.

- The charity pharmacy department should compute the clinical outcome of the charity pharmaceutical care services

- The charity pharmacy department should analyse the economic output of charity pharmaceutical care.

- The charity pharmacy department should document the implementation of charity pharmaceutical care and accomplishment.

\section{Plan Cost Management}

For each new project, the management team must find out the financial budget, counting the donated cost of educational courses, charity pharmaceutical care, the presented price of the management team of charity pharmaceutical care meetings, and updated references. The donated budget must be managed until the project finishes and switches to the operating system.

\section{Executing Phase}

\section{Management Team}

Project management professionals had multiple steps. One of the vital steps was executing phase, which had a team lead the program or the project from the beginning until becoming one of the operating systems at the charitable healthcare organization. The team comprised of several members, counting hospital distributive pharmacists, clinical pharmacists, pharmacy technicians, community pharmacies and pharmacy technicians, pharmacy quality management, and medication safety officers. In addition, the team should implement and follow up on the new services with regular updating of the charity pharmacy service. Finally, the team should educate and train the charity pharmacy staff about the new services and measure the clinical and economic consequences of the project.

\section{Education and Training}

Each new project entails special education and training for concern charitable people. This project needs education and training for charity pharmacy staff, counting clinical pharmacists, pharmacists, and pharmacy technicians. The charitable healthcare professionals, including physicians and nurses, need another special education and training. Moreover, the team management wants orientation education about the charity project for all charity healthcare professionals. The orientation importance on any charity new staff healthcare providers joined the charity healthcare organizations. 


\section{Monitoring and Controlling Phase}

\section{Project Total Quality Management}

There are numerous tools used for methods of quantity management with a new project, Charity pharmaceutical care during the execution phase, and imitate the impact. The balance scored cards was among them. ${ }^{26}$ The tools monitor contained of four parts: the customer, finance, internal process, education, and innovation. First, the assessment of charity pharmaceutical care at the healthcare services was an example of an internal process type. Second, the clinical outcome of charity pharmaceutical care might reproduce the education and competency of charity pharmaceutical care; the clinical pharmacists, distributive pharmacists, and pharmacy technicians an example of the education type. Third, the financial type had another example of calculating the cost avoidance of charity pharmaceutical care. The fourth type was the customer type measuring the patient's satisfaction with pharmacy staff providers, counting pharmacists and pharmacy technicians of charity pharmaceutical care satisfaction in Saudi Arabia.

\section{Risk Management}

There are multiple things measured as risks in the new project, counting schedule risks, scope risks, budget risks, personal risks, technical risks, and quality risks. The project is mainly uncovered to personnel, budget, technical, and quality risks. ${ }^{27,28}$ The project of charity pharmaceutical care properly agonised from personal threats with not trained pharmacy staff or adequate clinics pharmacists or pharmacists and pharmacy technicians. The budget risk not covered the charity pharmaceutical care education and training courses for all pharmacy staff and healthcare professionals. There is another technical risk unprotected to the technical, which is limited to charity pharmaceutical care electronic recourses in pharmacy practice. Finally, the project maybe exposed to quality risks with not applied in charity pharmaceutical care services tools or non-trained personnel.

\section{Closing of the Project}

The charity pharmaceutical care at all the healthcare organizations; interrelated to governmental and private sectors is obligatory to develop the pharmaceutical care services, to prevent drug-related errors that lead to morbidity and mortality, in the charity pharmacy, and evade redundant additional unnecessary cost on pharmacy and healthcare system healthcare organizations in Saudi Arabia. The project should endure at the Charity pharmaceutical care services at each pharmacy unit and keep supervision through related committees. The charity pharmaceutical care education and training should be executed accordingly. The charity pharmaceutical care services should be updated regularly, and inflate the number of programs is recommended in the future. The annual celebration of all charity pharmaceutical care pharmacy and healthcare staff is extremely acclaimed in Saudi Arabia.

\section{ACKNOWLEDGEMENT}

None.

\section{CONFLICT OF INTEREST}

The authors declare that there is no conflict of interest.

\section{Funding}

None

\section{Consent for Publications}

Informed consent was obtained from all the participants
OEthical Approval

This research is exempted from research and ethical committee or an institutional review board (IRB) approval.

https://www.hhs.gov/ohrp/regulations-and-policy/decisioncharts-2018/index.html

\section{ABBREVIATIONS}

MOH: Ministry of Health; KSA: Kingdom of Saudi Arabia; ASHP: American Society of Health-System Pharmacists; SWOT: Strengths, Weaknesses, Opportunities, and Threats; IV: Intravenous; BSC: Balance Scored Cards.

\section{ORCID ID}

Yousef Ahmed Alomi iD https://orcid.org/0000-0003-1381-628X

\section{REFERENCES}

1. Saudi Ministry of Health. Health statistical year. Bk. 2017. Saudi Ministry of Health; 2017.

2. Saudi Ministry of Health. Health statistical year. Bk. 2016. Saudi Ministry of Health; 2016

3. Government of Saudi Arabia. Saudi Arabia vision. Vol. 2030 [internet]; 2016. Available from: https://vision2030.gov.sa/sites/default/files/report/Saudi Vision2030_EN_2017.pdf [cited 19/8/2021]

4. $\mathrm{MOH}$ S. National e-health strategy $-\mathrm{MOH}$. Initiatives 2030 [Internet]. Ministry of Health Website. 2017

5. Alomi YA. New pharmacy model for vision 2030 in Saudi Arabia. J Pharm Pract. Commun Med. 2017;3(3)

6. Charity community health societies [internet] [cited Mar 29 2020]. Available from: https://www.moh.gov.sa/Documents/Existing-health.pdf.

7. Administration of scientific societies-scientific societies [internet] [cited Mar 29 2020]. Available from: http://www.aicss.org/BrowseCommitteesEN.asp.

8. Saudi Commission for Health Specialists. Heath societies [internet] [cited Mar 29 2020]. Available from: https://www.scfhs.org.sa/CouncilsGate/AboutCouncils/ Pages/default.aspx.

9. Salman K, Humanitarian Aid and Relief Center [internet] [cited Mar 29 2020] Available from: https://www.ksrelief.org/.

10. De Rosa A, Meyer A, Seabra AP, Sorge A, Hack J, Soares LA, Chalub S, Malcher F, Kingsnorth $A$. An international surgical collaboration: humanitarian surgery in Brazil. Hernia. 2016 Aug 1;20(4):553-7. doi: 10.1007/s10029-015-1407-0, PMID 26306470.

11. Leder HA, Rivera P. Six days in Charity Hospital: two doctors' ordeal in Hurricane Katrina. Ann Ophthalmol (Skokie). 2006;38(1):13-9. doi: 10.1385/ao:38:1:13, PMID 17200578

12. Wang $H$, Nejtek VA, Zieger D, Robinson RD, Schrader CD, Phariss C, Ku J, Zenarosa NR. The role of charity care and primary care physician assignment on ED use in homeless patients. Am J Emerg Med. 2015 Aug 1;33(8):1006-11. doi: 10.1016/j.ajem.2015.04.026, PMID 26001738.

13. Knight TG, Deal AM, Dusetzina SB, Muss HB, Choi SK, Bensen JT, Williams GR Financial Toxicity in Adults With Cancer: Adverse Outcomes and Noncompliance. J Oncol Pract. 2018:JOP1800120. doi: 10.1200/JOP.18.00120. PMID 30355027.

14. Davies E. Volunteer doctors start a clinic for the marginalized of New York City. BMJ. 2013;347:f7586. doi: 10.1136/bmj.f7586, PMID 24355388

15. Valdovinos E, Le S, Hsia RY. In California, not-for-profit hospitals spent more operating expenses on charity care than for-profit hospitals spent. Health Aff (Millwood). 2015;34(8):1296-303. doi: 10.1377/hlthaff.2014.1208, PMID 26240242.

16. Glanville M, Brady R, Miller S. Operation Donate: defining the value of redispensing medications donated by individuals. J Am Pharm Assoc (2003). 2014 Sep 1;54(5):542-7. doi: 10.1331/JAPhA.2014.11101, PMID 25216885.

17. Mohammed D, Turner K, Funk K. Pharmacy student involvement in student-run free clinics in the United States. Curr Pharm Teach Learn. 2018 Jan 1;10(1):41-6. doi: 10.1016/j.cptl.2017.09.008, PMID 29248073.

18. Wiesner AM, Steinke DT, Vincent WR, Record KE, Smith KM. National survey of pharmacy services in free medical clinics. J Am Pharm Assoc (2003). 2010;50(1):45-51. doi: 10.1331/JAPhA.2010.09013, PMID 20097639.

19. Oke TO. Primary health-care services with a functional ambulatory care clinical pharmacy in a low-income housing project clinic. J Natl Med Assoc. 1994;86(6):465-8. PMID 8078084

20. Babeaux HPF, Hall LE, Seifert JL. Charitable pharmacy services: impact on patient-reported hospital use, medication access, and health status. J Am Pharm Assoc. 2015 Jan 1;55(1):59-66. doi: 10.1331/JAPhA.2015.14010. 
21. Elrggal ME, Karami NA, Rafea B, Alahmadi L, Al Shehri A, Alamoudi R, Koshak H, Alkahtani S, Cheema E. Evaluation of preparedness of healthcare student volunteers against Middle East respiratory syndrome coronavirus (MERS-CoV) in Makkah, Saudi Arabia: a cross-sectional study. Z Gesundh Wiss. 2018 Dec 1;26(6):607-12. doi: 10.1007/s10389-018-0917-5, PMID 30533343.

22. McDonough R. Writing a business plan for a new Pharmacy Service. Health. 2010;23, The Dynamics of Pharmaceutical Care: Enriching Patients'.

23. American College of Clinical Pharmacy, Harris IM, Baker E, Berry TM, Halloran MA, Lindauer K, Ragucci KR, McGivney MS, Taylor AT, Haines ST Developing a business-practice model for pharmacy services in ambulatory settings. Pharmacotherapy. 2008;28(2):285. doi: 10.1592/phco.28.2.285. PMID 18225974
24. Sachdev G. Sustainable business models: systematic approach toward successful ambulatory care pharmacy practice. Am J Health Syst Pharm. 2014;71(16):1366-74. doi: 10.2146/ajhp140078, PMID 25074956.

25. PMBOK guide. A guide to the project management body of knowledge. Sixth edit. Project Management Institute, Inc; 2017.

26. Kaplan RS, Norton DP.The balanced scorecard-measures that drive performance. Harv Bus Rev. 1992;70(1):71-9. PMID 10119714.

27. Ray S. The risk management process in project management - ProjectManager.com [internet]; 2017. Project Manager [cited Mar 15 2020]. Available from: https://www.projectmanager.com/blog/risk-management-process-steps.

28. Kaplan RS, Mikes A. Managing risks: A new framework [internet]; 2012. Harvard Business Review [cited Mar 15 2020]. Available from: https://hbr.org/2012/06/ managing-risks-a-new-framework. 